\title{
A institucionalização da Gestão de Recursos Hídricos na Bacia Hidrográfica do Rio das Velhas, Minas Gerais, Brasil, sob a ótica democrática e participativa
}

\author{
Hildelano Delanusse Theodoro ${ }^{1 *}$, Nilo de Oliveira Nascimento ${ }^{2}$ e Léo Heller ${ }^{3}$
}

1*Autor correspondente: Escola de Engenharia, Universidade Federal de Minas Gerais (UFMG)

Avenida Antônio Carlos, 6627, Bloco 1, Sala 4619 - CEP 31270-901. Telefone: 31-3409-1882

2 Escola de Engenharia, Universidade Federal de Minas Gerais (UFMG).

${ }^{3}$ Fundação Oswaldo Cruz (FIOCRUZ)

ISSN 2448-0479

Resumo - Este artigo tem como objetivo identificar os principais processos de gestão de recursos hídricos da bacia hidrográfica do do Rio das Velhas' a partir de uma perspectiva democrática e participativa, enfatizando os aspectos de participação, práticas diferenciadas e transparência. A discussão proposta tem como objetivo mostrar as diferenças entre os processos decisórios e a definição de uma agenda institucional sobre Rio das Velhas que, apesar de ser considerado uma dos mais importantes bacias hidrográficas no estado de Minas Gerais, seus processos de governança institucional ainda não são plenamente conhecidos. Para isso, uma análise triangular foi efetuada tendo em conta o seu aspecto teórico, pesquisa de campo e entrevistas individuais com lideranças, de acordo com o conceito de triangulação de métodos de pesquisa. Como principais conclusóes deste trabalho, é importante ressaltar tanto as dificuldades para o Comitê da Bacia Hidrográfica do Rio das Velhas consolidar um modelo de gestão democrática e participativa, como também a necessidade de autonomia para garantir açoóes institucionais próprias, em um cenários com fortes interesses estatais.

Palavras-chaves - Governança. Gestão de recursos hídricos. Políticas públicas. Gestão institucional. Comitês de bacia.

Abstract - This article aims to identify the main management processes of water resources of the watershed of the river named 'Rio da Velhas' from a democratic and participative perspective, emphasizing the aspects of participation, differentiated practices, and actual transparency. The proposed discussion aims to show the gaps between the decision making processes and the definition of an institutional agenda regarding the Rio das Velhas watershed that, in spite of being regarded as one of the most important watershed in the state of Minas Gerais, its institutional governance processes remain to be well-known. To that, a triangular analysis has been carried out by taking into account its theoretical aspect, and as well field surveys, and individual interviews with water resources management leaders engaged in such work objective according to the concept of research method triangulation. As the main findings of this work, it is worth pointing out both, the remarkable institutional insubstantiality of the Rio das Velhas watershed committee to consolidate a democratic and participative management model, and as well the autonomy required to ensure such institutional substantiality remains strongly tied to actions determined by the state government interests.

Keywords: Governance. Water resources management. Public policies. Institutional management. Watershed committees.

Recebido em: 18 de maio de 2016

Aprovado em: 11 de julho de 2016 


\section{INTRODUÇÁO}

Considerada como uma das grandes questôes em discussáo sobre os cenários presentes e futuros da gestão de recursos hídricos no mundo e no Brasil em particular, o conceito de governança tem sido analisado e revisitado por diversos atores sociais, individuais ou institucionais, e com vários níveis de profundidade e entendimento. Mesmo náo sendo uma unanimidade em termos de sua aplicação e, ou capacidade de explicação científica, administrativa ou política, o fato é que sua influência é inegável no cenário intelectual das últimas décadas e tem dado provas de fôlego a prosseguir em evidência.

E tal destaque nâo se dá por acaso; ao contrário, a análise da governança em suas influências nos cenários mais variados é fruto de um processo de reflexão institucional sobre quais as demandas que o complexo âmbito de atuação do Estado no mundo contemporâneo tem capacidade ou náo de tentar dar respostas, em qual tempo, em qual lugar e para quais comunidades, ainda mais a se considerar o campo ambiental de debate (GIDDENS, 2010; CUNHA; THEODORO, 2014). Mesmo tendo surgido por meio de influências corporativas oriundas dos setores econômico-financeiro de nível internacional (BANCO MUNDIAL, 1992), o conceito de governança, ou melhor, o de "boa governança", foi difundido em larga escala, menos por propor medidas de comando e controle tradicionais e mais por iniciar uma série de discussóes sobre o (pretendido) aprimoramento das estruturas públicas por meio de processos de inclusão e controles sociais diversos. Certamente que tal posicionamento gerencial deve ser entendido dentro de um contexto e de um arcabouço teórico e institucional, o que náo livrou o conceito de ser analisado de forma crítica inúmeras vezes.

Neste sentido, o presente trabalho busca identificar, sob a ótica democrática e participativa que fundamenta conceitualmente boa governança, a dinâmica institucional e organizacional existente em uma bacia hidrográfica determinada. A selecionada foi a do Rio das Velhas, localizada em Minas Gerais, terceiro estado-federado mais importante em termos econômicos e industriais no Brasil, por meio do estudo das restriçóes e potencialidades de atuação de seu comitê, que foi instituído pelo Estado no ano de 1998, justamente 10 anos após a nova Constituição Federal do país ser promulgada. Além disso, o comitê surgiu apenas 1 ano após a principal legislação brasileira sobre re- cursos hídricos se tornar oficial (Lei Federal no 9.433, de 1997) e 1 ano antes de se ter a Política Estadual de Recursos Hídricos em Minas Gerais (Lei Estadual no 13.199). Inclusive, a demora na formulação de uma lei nacional sobre o tema no Brasil acabou por fazer com que vários estados criassem suas próprias leis regionais (TORTAJADA, 2001), próximo ao que aconteceu no território mineiro.

Cabe ressaltar também que o Brasil tem como forma de governo o modelo de república federativa, que é dotado de 27 unidades administrativas e com 3 níveis e escopos distintos para as tomadas de decisóes institucionais (municipal/local; estadual/regional; fe$\mathrm{deral} /$ nacional). Isso faz com que a gestão de recursos hídricos adquira uma complexidade organizacional que demanda maior conhecimento e aprimoramento de seus instrumentos de gerenciamento. Mais ainda, o estado-federado de Minas Gerais possui o maior número de municípios do país, 853 , e somente a bacia hidrográfica do Rio das Velhas, objeto desta pesquisa, compreende 51 municípios distribuídos em seus $29.173 \mathrm{~km}^{2}$ de área de drenagem e com $801 \mathrm{~km}$ de extensão da calha principal do rio, ou seja, a distância em linha reta entre o ponto mais distante da foz e esta (COMITÊ DA BACIA HIDROGRÁFICA DO RIO DAS VELHAS, [2014?]; CAMARGOS, 2005).

Nesse sentido este artigo se determina a estudar qual o alcance do papel do Comitê da Bacia Hidrográfica do Rio das Velhas (CBHRV) na gestão de recursos de seu território de competência - vide Figura 4, assim como delimitar o limiar da existência de autonomia ou controle por parte do Estado em termos das decisóes deste e da consolidaçấo de um modelo participativo real. Parte-se do pressuposto de uma atuaçáo ambígua do Estado, ora a concordar com a autonomia dos organismos de bacia, ora a controlá -los em suas práticas institucionais.

Consequentemente, se colocam aqui as questóes levantadas por vários autores que tratam sobre o conceito de boa governança, considerado dentro desta pesquisa como um dos modelos de gestão possíveis de serem aplicados em um dado contexto institucional. Tal possuiria como característica a incorporação de determinados critérios, a depender das perspectivas de análise, tais como: Rogers e Hall (2003); Warner (2007); Mayntz (2000), etc. As mesmas, de forma geral, buscam a formação e consolidação do gerenciamento democrático e participativo, mesmo que, por vezes, dentro de um cenário de mudanças e intervençóes aos interesses estatais (SWYNGEDOUW, 
2005). Salienta-se aqui, inclusive, que os cenários de mudanças institucionais são recorrentes no caso brasileiro, com maior ou menor valorização de instâncias e processos participativos.

Nessa direção, o artigo busca identificar quais os elementos institucionais que o CBHRV traz enquanto modelo de boa governança a partir de alguns critérios que foram escolhidos por representarem possibilidades de explicaçáo mais amplas e concatenadas com a proposta deste artigo. Nesse sentido, os critérios de participação, transparência e ações diferenciadas foram os escolhidos para comporem um rol de avaliação do CBHRV, mas outros critérios tais como tipo de desenho institucional, historicidade, legitimidade, legalidade, etc também poderiam fazer parte de uma análise de gestão institucional, mas possivelmente a gerar encaminhamentos diferentes do que aqui é trabalhado. Vale também se destacar que o que considera como "açóes diferenciadas" é o conjunto de intervenções que não sâo utilizadas usualmente em modelos de comitês de bacia hidrográfica, não sendo necessariamente inovaçôes na gestão e mais assimilaçôes, adaptaçôes de modelos usuais de gestão hídrica (com exemplos a serem demonstrados adiante).

No caso específico do Brasil, o estudo da aplicação de princípios de governança é uma possibilidade para o aprimoramento do setor público e de suas decisões políticas e administrativas. Sendo um dos principais atores no cenário ambiental do século XXI, o país tem colocado, em vários de seus Estados-membros, arranjos institucionais participativos para a gestão hídrica, seja por meio de legislação mais abrangente para tal, seja pela instauração de arenas de planejamento, consulta ou deliberação coletiva. Tal como descrito, o Brasil possui um caráter federativo onde a gestão de recursos hídricos se dá por meio da unidade de planejamento e integração principal que é a bacia hidrográfica, inclusive com determinação legal para tanto (Lei no 9.433 , de 1997); ver Figura 1.

Dentre suas instituiçôes componentes se encontram:

a) Organismos Colegiados: Comitês de Bacia Hidrográfica $(\mathrm{CBH})$; Conselhos Estaduais de Recursos Hídricos (CERH); Conselho Nacional de Recursos Hídricos (CNRH). Responsáveis pelas discussões e resoluções de conflitos ao nível das bacias;

b) Administração Direta: Secretarias de Estado; Ministério do Meio Ambiente (MMA)/Secretaria Nacional de Recursos Hídricos (SRH). Responsá- veis pelo gerenciamento institucional e estrutural da Política Nacional de Recursos Hídricos.

c) Poder Outorgante: Entidades Estaduais (no caso de Minas Gerais, o Instituto de Gestão das Águas - IGAM); Agência Nacional de Águas (ANA). Responsáveis pela aplicação dos instrumentos de gestão ao nível administrativo.

d) Entidade de Bacia: Agências de Bacia. Responsáveis por executar e ajudar administrativa e juridicamente aos Organismos Colegiados.

E nessa estrutura é que se encaixam os Comitês de Bacia Hidrográfica $(\mathrm{CBH})$ como um dos principais exemplos possíveis dessa tendência de ampliação da democracia e da participação coletiva multiníveis, mesmo que ainda em consolidação e em prática não majoritária de aplicação em todo o território, devido às suas inerentes características. Normalmente o modelo de participação é tripartite, de forma que cada setor setor seja representado, mas sem a prevalência de um sobre os outros. Já no modelo quatripartite do CBHRV, a divisão entre poder público municipal e estadual foi estipulada para possibilitar maior participação ao poder local, que possui lógica de atuação diferente da regional.

O referido objeto (Comitê da Bacia Hidrográfica do Rio das Velhas, ou CBHRV) foi selecionado na medida em que propicia o estudo de um organismo de bacia hidrográfica que se encontra em atuaçâo há mais de 15 anos, sendo assim um dos mais antigos do país, como também por ser aquela bacia à qual pertence a capital do estado-federal em questão, Belo Horizonte. Isto lhe confere caráter particularizado no contexto da governança a ser exercida, uma vez que, conjuntamente com a bacia hidrográfica do Rio Paraopeba, que lhe é vizinha, tem-se a mais rica e populosa região metropolitana do estado de Minas Gerais. Mais ainda, dos 34 municípios que a compóem, 20 possuem território na bacia do Rio das Velhas e se encontram representados no CBHRV. O comitê em si, em termos de sua composição, possui 28 membros titulares (e 28 suplentes) que, em um sistema quatripartite, estão representados em igual número de 07 membros por segmento (sociedade civil, usuários de água, poder público estadual, poder público municipal). Eles são eleitos para um mandato de 04 anos, passível de reeleição, e com a realização de reuniōes ordinárias e/ou extraordinárias (denominadas de "plenárias") para a definição de suas ações a cada ano.

Além disso, existem 04 Câmaras Técnicas (CT's) 


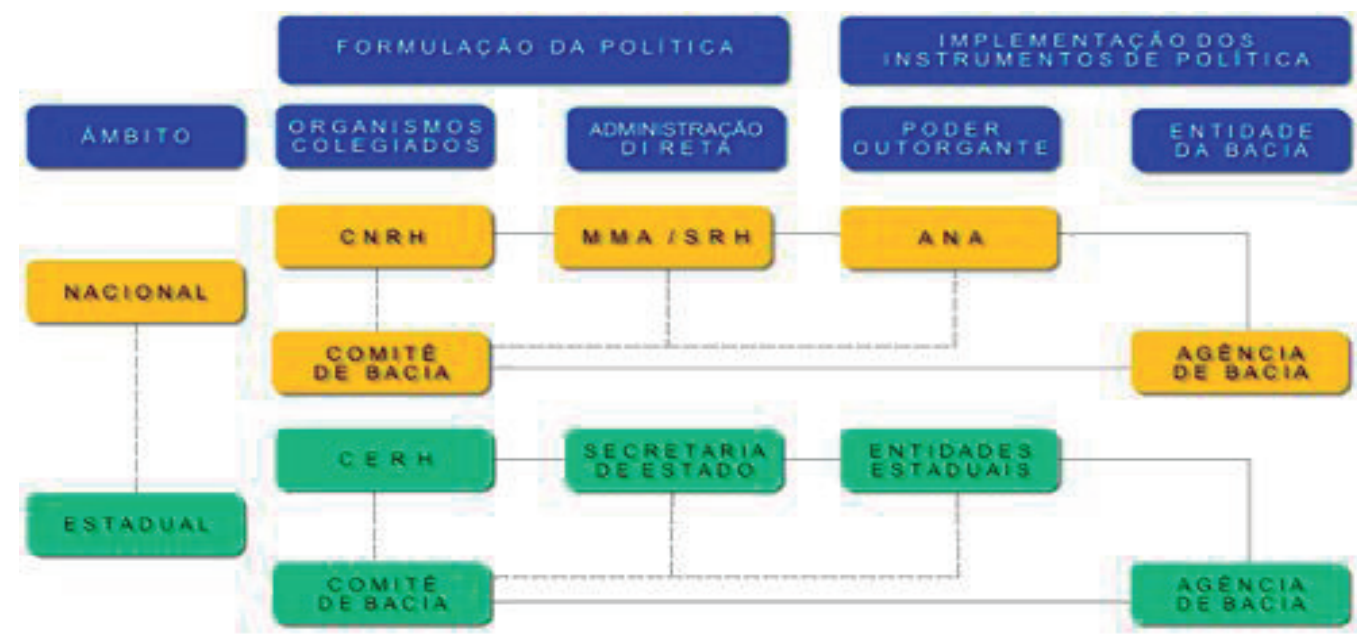

Figura 1 - Sistema Nacional de Recursos Hídricos

Fonte: Agência Nacional de Águas (2012)

onde membros e náo-membros podem interagir sobre aspectos específicos da gestão do comitê: a) Planejamento, Projetos e Controle; b) Educação, Mobilização e Comunicação; c) Institucional Legal; d) Outorga e Cobrança). A eleição, deve-se destacar, é parte de um processo de chamada pública, onde as instituiçôes são selecionadas a partir de critérios técnicos-administrativos (vinculaçẫo com a temática ambiental e hídrica; histórico de participação em movimentos sociais e ambientais; representatividade comprovada em segmento próprio etc). Após esta seleção prévia, dão-se os processos de interação entre os atores e suas instituiçôes para a definição dos nomes que irão compor os níveis de decisão estabelecidos (presidência, vice-presidência, diretoria colegiada, câmaras técnicas).

A discussão proposta pretende evidenciar lacunas existentes nos processos de tomada de decisão e de definição da agenda institucional em relação à bacia hidrográfica referida que, mesmo sendo considerada uma das mais importantes do Estado de Minas Gerais, ainda demanda maior conhecimento de seus processos institucionais de governança. Pretende-se aqui, igualmente, relatar e avaliar as transformaçôes institucionais na gestấo dos recursos hídricos na bacia pesquisada e de como a governança foi sendo gradativamente colocada na agenda pública pelo Estado (SWYNGEDOUW, 2005; GREEN, 2007).

O enfoque priorizado dentro do escopo da temática da boa governança da água é o da articulação dos atores institucionais para processos de gestão democrática e participativa. Mais ainda, a boa governança e suas argumentaçôes teóricas podem cooperar para o entendimento, neste trabalho, sobre os principais problemas que afetam a bacia hidrográfica do Rio das Velhas, a partir dos dados coletados em campo aliados à análise documental e histórica proposta (MINAYO, 2012).

Cabe salientar que o termo governança possui várias leituras, nem sempre congruentes entre si $\mathrm{e}$ que demonstram a diversidade de possibilidades que, conceitualmente, o termo absorve (GREEN, 2007). Nessa direção, vale destacar as contribuiçốes de Dourojeanni e Jouravlev (2002) e de Tucci (2001) - de tendências mais convencionais - como também de Tortajada (2001), Castro (2007) ou Swyngedouw (2005) - de tendências mais críticas que permitem revelar que a a gestão enquanto processo de governança pode criar ambientes e resultados diferenciados de entre si. Outrossim, a própria proposta de gestáo a partir da bacia hidrográfica, mesmo que considerada como um avanço administrativo ainda é bastante controversa em sua aplicação (ABERS, 2010; SOARES, 2008; THEODORO; MARQUES, 2014; TORTAJADA, 2001). Em uma bacia de proporção tâo extensa e de níveis diferenciados de estrutura física, econômica e social (CAMARGOS, 2005; THEODORO; MARQUES, 2014) como se tem no Rio das Velhas, práticas diferenciadas de gestáo integrada também são demandas para soluçóes complexas que envolvem direitos difusos como os hídricos (GREEN, 2007; ROGERS; HALL, 2003; ABERS, 2010; ABERS; KECK, 2013).

Para Mayntz (2000) o termo pode ser compreendido como denominação de forma de direcionamento governamental que tem a ambiçáo de ser associado a um conhecimento dos interesses e valores das 
pessoas (RICHARD; RIEU, 2008). Na atualidade, caracterizaria novos estilos de governo que sejam distintos da atuação hierárquica tradicional, com a incorporação maior de redes de decisão mista entre público e privado, assim como de atores não governamentais da sociedade.

Desta forma, houve uma maior abrangência de significados do termo durante as últimas décadas, desde sua caracterização paradigmática fundamental de elaboração e implementação de políticas públicas até a inclusão de diversos aspectos (perspectiva bottom-up; redes pública-privadas, déficit de democracia etc), o que colocou o termo em situações inclusive conflitantes e que foram derivadas das inclinaçôes conceituais de seus autores (GREEN, 2007). Para Rogers e Hall (2003), por exemplo, a "governança" pode ser entendida como a alocação e regulação políticas entre sociedade e governos, por meio de mediação via valores, normas e, quando possível, legislações. Considera que as redes de influência, atividades domésticas e setores de mercado e sociedade civil são aspectos relevantes para a governança.

Assim, uma demonstração da nova forma de atuação dos governos passaria pela incorporação de novos atores vindos do mercado e da sociedade civil como possibilidade de recuperação da confiança da atuação institucional governamental e do estabelecimento de um novo patamar de democracia participativa, com mais espaços para a construção de diálogos institucionais (SOARES, 2008; WARNER, 2007; ABERS, 2010; CUNHA; THEODORO, 2014).

Outrossim, o conceito de governança que se encontra na literatura dominante idealiza um rol de interações entre governo-mercado-sociedade civil que se tornou central nas discussóes das políticas públicas ("tri -partite partnership") - também presente em Cunha e Theodoro (2014) e Theodoro (2002) - porém Castro (2007) alerta que esse balanço de forças necessitaria ser examinado com maior rigor, pois correria o risco de não explicar todos os complexos arranjos institucionais existentes e seus conceitos. Assim também indica Swyngedouw (2005) em que a "composição tripartite" não é igualitária, nem participativa, nem democrática como se supóe. Ou seja, não basta que se tenha uma divisão igualitária de representação formal-institucional para que um processo de gestão democrática, descentralizada e participativa ocorra realmente.

E para Richard e Rieu (2008), o termo "governança" se impôs a partir dos anos 80-90 como um símbolo de uma nova modernidade dentro dos mo- dos de ação das políticas públicas, e foi sendo paulatinamente incorporado pelos economistas, até alcançar a expressão de "boa governança". Esta foi rapidamente utilizada por instituiçôes financeiras internacionais como sinônimo de boa administração pública (em termos de estratégias e implementação de açóes), principalmente em países sujeitos a programas de ajustamento estrutural, como o Brasil.

Sendo assim, o Banco Mundial (como depois outros organismos tais como PNUD, FMI, OCDE, dentre outros) foi a primeira instituição internacional a utilizar o termo "governança" como: "...a maneira pela qual o poder é exercido na gestão dos recursos econômicos e sociais de um país a serviço do desenvolvimento". (BANCO MUNDIAL, 1992, p. 1).

Ao se traduzir estas estruturas para o desenvolvimento institucional que ocorreu nas políticas públicas de água do Estado brasileiro e em Minas Gerais especialmente, nota-se que houve o envolvimento das mesmas em diversas fases da consolidaçấo da gestão. A grosso modo a situação atual é a prevista em lei, porém deve ser entendida como resultado de um longo processo de debate para a construçáo de um modelo de governança ao setor hídrico. Mais ainda, houve um importante papel de mobilização inicial alavancado pelo Estado para a criação e estruturação dos CBH's. Essa importância até hoje existe nos comitês brasileiros e faz com que muitas vezes açôes de iniciativas dos setores sociais sejam coadjuvantes ou dependentes dessa trajetória institucional estatal inicial.

E a partir das discussóes anteriormente citadas e na falta de consenso conceitual existente (GREEN, 2007), "boa governança" é utilizada neste trabalho como uma das formas de gestão possíveis, porém sendo aquela em que se tem um modelo de gestão com maior democracia e participaçáo dos atores envolvidos, - o que se aproxima da definiçấo de dada por Kooiman (1993) apud Richard e Rieu (2008). A escolha por esta definição se dá pela explicação de que os grupos diversos interagem para (tentar) criar um ambiente consensual mínimo para açôes democráticas e participativas.

O que a gestão democrática e participativa hídrica poderia exprimir a partir dessa noçâo seria da interdependência entre os atores públicos e privados e da interação constante entre diferentes para a criaçáo de consensos coletivos para situaçōes de gestão diversas frente às açóes estatais que por vezes mais controlam do que criam autonomias de ação (SWYNGEDOUW, 2005). 
Assim, existe um reconhecimento de que têm havido avanços na consolidaçáo de um modelo mais participativo e democrático de gestão institucional, mas que há de se ter também certa maturidade de se entender que o sistema para tal caminha ainda de forma lenta e que tem por base um arcabouço jurídico e institucional muito recente (tal como a criação da agência reguladora, a Agência Nacional de Águas (ANA), que é de 1999, ou o Instituto Mineiro de Gestão das Águas (IGAM), que é de 1997) - vide Figura 2. Em realidade, todo o processo de institucionalizaçấo da gestão de recursos hídricos é relativamente nova no país, a ver:
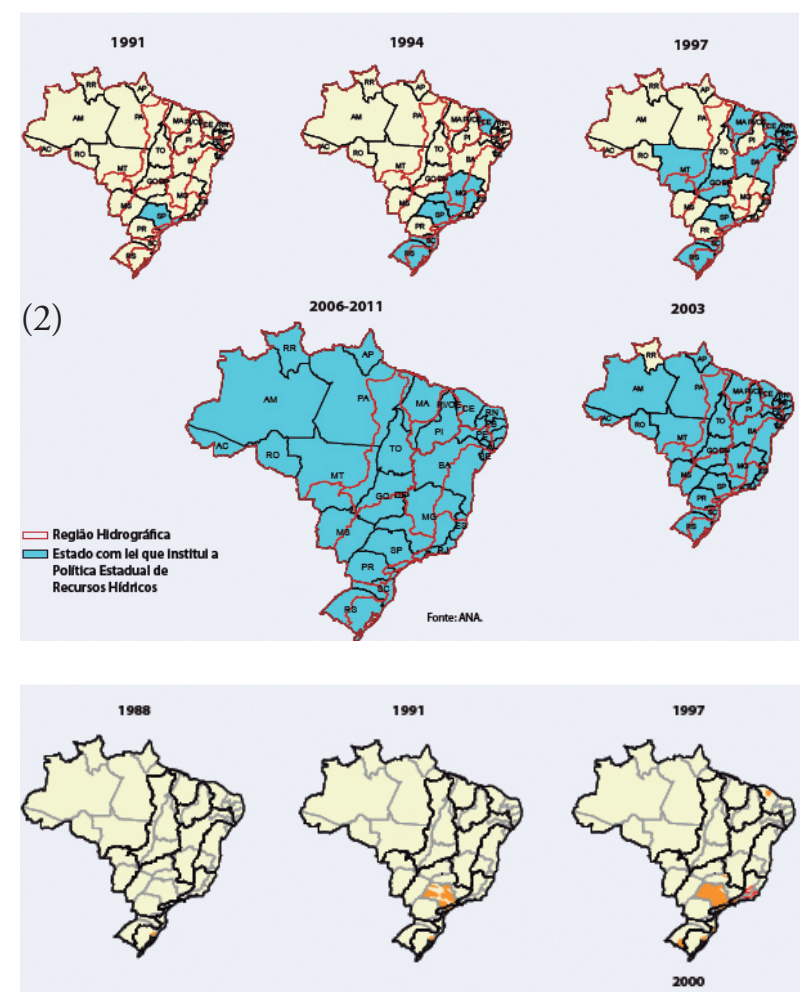

(3)
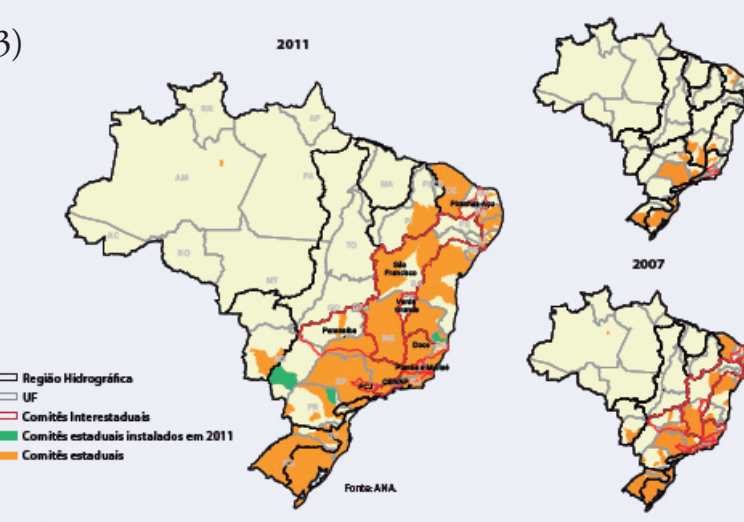

Figuras 2 e 3 - Avanço da institucionalização das políticas públicas estaduais de recursos hídricos (1) e da implementação de comitês de bacia hidrográfica no Brasil (2). - Modificadas

Fonte: ANA (2012)

\section{METODOLOGIA}

Para o desenvolvimento da pesquisa foi feita uma análise triangular que envolve tanto o aspecto teórico ("análise documental"), como de campo ("observação participante") e de entrevistas individuais ("análise de conteúdo"), o que é considerado dentro do conceito de "triangulação de métodos" já discutido por GOLAFSHANI (2003), FLICK (2009) e, principalmente, MINAYO et al (2005), de forma a dar ao fenômeno investigado, mais capacidade de ser explicável, confiável e validado.

Essa conjunção de métodos e técnicas de pesquisa foi escolhida na medida em que, atualmente, já se percebe na pesquisa qualitativa uma solidez suficiente para ser empregada como instrumento de pesquisas em geral e, em particular, por se adequar ao estudo de contextos complexos (FLICK, 2009). Mesmo que tradicionalmente as pesquisas se construam muitas vezes apenas nos elementos quantitativos de análise, a interação entre técnicas tem sido cada vez mais adotada (MINAYO, 2012; MINAYO et al., 2005; THEODORO; MARQUES, 2014) para tentar explicar, mais do que descrever, processos institucionais.

Destaca-se assim que a principal fonte de coleta e análise de dados desta pesquisa está relacionada com 25 entrevistas realizadas com indivíduos de destaque tanto na gestão de recursos hídricos quanto nas análises desta, sendo aqui considerados como lideranças em suas áreas de atuaçáo e com relaçóes diretas ou indiretas com o CBHRV. Buscou-se refletir na escolha dos entrevistados a representatividade quatripartite do comitê pela participação de indivíduos pertencentes a vários grupos de interesses, além de elementos externos ao mesmo mas que dele têm conhecimento continuado.

Observados esses critérios, os entrevistados provêm dos seguintes segmentos: Usuários (5); Sociedade Civil (6); Poder Público Municipal (2); Poder Público Estadual (1); e de Instituiçóes/Organizaçóes (8) - tais como a agência de água do Rio das Velhas, denominada de "AGB Peixe Vivo" e universidades. Utilizou-se um roteiro padráo de entrevista aplicado a cada entrevistado, requerendo um tempo de entrevista da ordem de 50-60 minutos. O roteiro foi composto por 18 perguntas semi-estruturadas abertas sobre 8 diferentes categorias analíticas, a saber: uso e ocupaçâa do solo; qualidade de água; quantidade de água; bioindicadores; dimensão institucional; dimensão integradora; dimensão legal; dimensão econômica-financeira. Salienta-se que neste artigo encontram- 
se contempladas as análises dos temas das dimensóes institucional, integradora, legal e econômica-financeira, com ênfase sobre a primeira.

Para a análise de dados, empregou-se a "análise de conteúdo" (BARDIN, 1994), em que se tenta identificar argumentaçóes diretas e indiretas dos discursos dos atores envolvidos, de maneira a se formar um panorama mais abrangente (e ao mesmo tempo, mais próximo) sobre o objeto escolhido. O que se esperava com as entrevistas era destacar quais as principais restriçóes e possibilidades de melhorias institucionais nos processos de gestão de recursos hídricos no Rio das Velhas, para possibilitar uma análise longitudinal dos mesmos (GREEN, 2007), principalmente em termos das 4 dimensóes de pesquisa anteriormente descritas. Esperava-se também a identificação das nuances e dos bastidores das tomadas de decisóes e das açôes políticas dos diversos grupos representados no CBHRV.

Isto permitiu se verificar as "presenças" e "ausências" nos relatos que, com a utilização de outras técnicas, de forma isolada, seriam mais difíceis de serem detectadas, uma vez que aqui se admite a concepção da análise qualitativa como algo mais do que classificação de opiniōes de informantes e sim como descoberta de seus códigos sociais (MINAYO, 2012). Também como suportes metodológicos para a pesquisa foram utilizadas as principais documentaçôes referentes ao desenvolvimento das políticas públicas vinculadas à gestáo da bacia hidrográfica do Rio das Velhas, tais como legislações, deliberações normativas e afins, assim como os dados levantados em campo ("observação participante"), de forma não sistemática mas decorrente da experiência vivenciada pelo primeiro autor deste trabalho no decorrer de vários anos como membro do próprio comitê e do Comitê da Bacia Hidrográfica do Rio São Francisco (CBHSF), uma vez que o Rio das Velhas é tributário deste.

Essa abordagem permitiu uma visão mais completa sobre as restriçôes e possibilidades de atuação do comitê referido, assim como sobre o sistema de gestâo de forma geral, pois tanto o meio físico (uso e ocupaçáo do solo), quanto biótico (quantidade e qualidade de água, bioindicadores), quanto antrópico (dimensóes de atuação do CBHRV - institucional; integradora; legal; econômica-financeira), foram incluídos e discutidos. As análises de conteúdo possibilitaram a identificação de lacunas institucionais, uma das hipóteses da pesquisa, além de demonstrar que o método qualitativo é pertinente, entre outras coisas, porque sobre o tema em questáo há pouco o que se quantificar e mais a se explicar em termos dos critérios empregados sobre participação, transparência e práticas diferenciadas, com vistas a processos mais democráticos de gestão.

Tais temas, à luz de uma análise de conteúdo, combinada com a interseção de dados documentais, de campo e de interaçôes face a face, foram primordiais para que os resultados a seguir fossem conseguidos, frutos do que Minayo (2012, p. 14) chama da união entre:

[...] a teoria da abordagem (o método), os instrumentos de operacionalização do conhecimento (as técnicas) e a criatividade do pesquisador (sua experiência, sua capacidade pessoal e sua sensibilidade").

Essa postura de composição de técnicas se coaduna com as observaçóes de BERGMANN (1985) apud FLICK (2009) de que cada uma delas (observação participante, entrevistas e análise de conversação) "...revela e obstrui diferentes pontos de vista sobre os fenômenos em estudo".

\section{RESULTADOS E DISCUSSÁO}

O CBHRV possui um arranjo institucional, administrativo demográfico e jurídico que teve na sua base a proposta de uma gestão descentralizada, democrática, participativa e integradora. O que se percebeu dos elementos avaliados é que os determinantes da criaçấo institucional deste comitê teriam de ser entendidos, no mínimo, em seu caráter contextual. Como vimos, o conceito de boa governança que orientou a concepção do comitê não surgiu por um acaso mas sim inserido nas políticas internacionais de agências multilaterais que determinaram organizaçóes mínimas de suposta participação social democrática (BANCO MUNDIAL, 1992; ROGERS; HALL, 2003; GREEN, 2007) como condicionalidades para o financiamento de empreendimentos variados de infraestrutura, sendo a área de recursos hídricos um exemplo tradicional de demanda desse tipo de apoio financeiro. Ao mesmo tempo, o Brasil se encontrava a partir de meados dos anos 1980 em um processo de redemocratização de suas instituiçóes e tal momento também deve ser considerado em uma análise longitudinal e organizacional mais ampla (ou seja, que leve em conta as transformaçôes institucionais de longo prazo). 
O período resultou em novos arranjos políticos e administrativos de decisão e de implantaçáo de políticas públicas. Ou seja, existiram fatores endógenos e exógenos que se complementaram para que a criação de organismos de bacia, no caso do Brasil e de Minas Gerais, fosse realizada.

Destaca-se então que o comitê é uma representação desse contexto em que o próprio Estado (anteriormente um centralizador das decisôes) foi o principal incentivador da formação do CBHRV, com a proposta, inclusive, de autonomia para a realização de suas funções (THEODORO, 2002; THEODORO; MARQUES, 2014; ABERS, 2010). O modelo de comitê, de base consultiva e deliberativa, com ampla participação pública e privada, dentro de processos abertos de acesso e saída de seus membros, foi uma característica explicitada desde sua gênese (CAMARGOS, 2005; GOULART, 2005; PROJETO MANUELZÃO, [2012?]), dentro da pretensão de se estabelecer como uma proposta muito próxima da colocada por Swyngedouw (2005) em termos de uma "governança-além-do-Estado".

Contudo, o conjunto de dados de campo, juntamente com as entrevistas com lideranças, indicou que a implementação desse cenário de "multi arenas de interação democrática" (WARNER, 2007) foi fortemente questionada. Para alguns, o modelo saiu do papel apenas parcialmente e ainda tem muito o que ser debatido, aprimorado e implantado. Uma das questóes consideradas é a representatividade institucional no âmbito do comitế; por exemplo, há maior concentração de subcomitês na parte mais urbanizada da bacia - vide Figura 3; as reunióes para tomadas de decisões geralmente são realizadas na capital do Estado, Belo Horizonte, o que pode ser um fator limitante para a participaçáo de representantes de entidades localizadas distantes da sede do Comitê. Outros fatores mais sutis relacionados com o equilíbrio de participação e de composição da agenda do Comitê referem-se, por exemplo, à diversidade de ocupaçáo da bacia e de uso dos recursos hídricos e de outros recursos naturais (ver Figura 4). A composição da agenda de questóes a debater e decidir e a organização dos processos de participação democrática dependem do contexto de cada regiáo na bacia. Mais ainda, foi verificado que nos últimos anos, a estrutura institucional para a gestão de recursos hídricos em Minas Gerais como um todo e no CBHRV em especial foi muito dilapidada e colocou, por vezes, os atores sociais em rotas de colisão.
O caso mais emblemático, a título de ilustração, foi o choque de posiçôes entre Estado e comitê em relação à organização da equipe de mobilização deste último e que já tinha atuação em toda a bacia hidrográfica há vários anos. Isso colocou a agência de águas (denominada Agência de Bacia Peixe Vivo - AGBPV) em conflito com o CBHRV e com o Instituto Mineiro de Gestão das Águas (IGAM) em várias ocasiōes e gerou um período turbulento e de impasses na gestão da bacia, sendo considerado por muitos como uma crise institucional real ao final do ano de 2012.

Naquele ano, por exemplo, devido às leituras antagônicas sobre a legalidade ou não da existência de equipes de mobilização social para atuação na bacia do Rio das Velhas, assim como que o CBHRV possuísse sede própria, o Estado se colocou fortemente contra ao modelo até então existente e demandou um novo desenho operacional sobre o assunto. Isso gerou desgastes constantes entre as partes até a normalização da situação, com a restauração das açôes de mobilização social por meio de equipe selecionada por chamada pública.

Explica-se: o papel das equipes de mobilização era e é o de fazer a interação entre os atores sociais da bacia hidrográfica de forma a se consolidar o processo de gestão democrática, participativa e descentralizada. Porém, o financiamento da mesma não estava, segundo o Estado, de acordo com as determinaçóes legais da Lei no 9.433/97 e, até o ajustamento legal e administrativo, a equipe de mobilização foi dissolvida e eventualmente restabelecida, em um processo que demorou quase um ano para ser finalizado. Enquanto para Estado e AGBPV era uma questão de ajustamento jurídico e administrativo, para o CBHRV era uma questão de continuidade de uma política de gestáo participativa que foi naquele momento interrompida. Consequentemente o conflito se deu entre os agentes.

Talvez aí se encontre um tema muito frequente no conteúdo das entrevistas, o fato de que tanto a agência quanto o comitê são percebidos por muitos dos entrevistados como menos autônomas do que o que foi pensado inicialmente (tal como os modelos da França $^{1}$ e da Espanha ${ }^{2}$ ). No fim das contas, a agência tem sido percebida, por vezes, menos como o órgáo executor das demandas do comitê, como previsto em legislaçáo, e mais como um braço institucional de intervenção do Estado, e não além dele, como sugere

\footnotetext{
${ }^{1}$ France (2014).

${ }^{2}$ Swyngedouw (2013).
} 
Swyngedouw (2005). Isso talvez se deva ao fato de que a AGBPV atua, administrativamente, por processos de licitação (principalmente pela Lei Federal 8.666/93), que trariam isonomia entre os atores sociais e institucionais envolvidos. Mas, na prática, são vistos como procedimentos de retardo às demandas colocadas no CBHRV e considerados como "cartoriais”. Ou seja, existem decisōes já tomadas, mas que sáo consideradas de tardia implantaçáo pelos membros do CBHRV, tais como a realizaçâo de planos diretores de saneamento ou projetos hidroambientais, ambos ao nível municipal ${ }^{3}$.

Outro problema constatado é que a maioria destes processos decisórios acontece em termos de consideraçóes políticas e/ou econômicas de curto prazo que desmerecem arranjos sociais que são inerentemente de longo prazo (integração institucional, participação e democratização das arenas consultivas etc). $\mathrm{O}$ caso das dificuldades para a instalação de subcomitês realmente operacionais no território da bacia é um exemplo a ser considerado, visto que muitas vezes não há um suporte administrativo para que os mesmos atuem. Na mesma direção, é possível se identificar que o foco da emergente cultura da água é sobre seu compartilhamento, descentralizado, entre atores sociais assimétricos em poder, localização e recursos, o que aumenta a demanda pela integraçáo via modelos de cooperação social e institucional. $\mathrm{O}$ fato é que, tal como alerta Abers et al. (2009), a própria descentralização atua como uma nova abordagem nas políticas públicas e que deveria ser também um fator considerado na construção da agenda política para ir além das açóes tradicionais estatais (SWYNGEDOUW, 2005). Os próprios comitês, por exemplo, podem adquirir sua justificativa de permanência se, por um lado, representam novas alternativas aos processos tradicionais de voz (representação) e voto (deliberação) e demonstrarem capacidade de interagir em termos de micro e macropolíticas.

Com este cenário, a governança hídrica alcança um novo patamar ao tentar ser uma abordagem em que a integração na gestão da água possa ocorrer mesmo que por meio das resistências iniciais institucionais ou sociais (visto que redimensiona deveres, direitos e, principalmente, poder decisório) $(\mathrm{GOOCH}$; HUITEMA, 2004).

Estas resistências precisariam então ser compreendidas por uma visão holística da gestão para que se te-

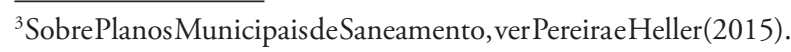

nha um planejamento/execução compatível para ações de nível estratégico e local conjuntamente que superem (ORGANIZAÇÃO DAS NAÇÓES UNIDAS PARA A EDUCAÇÁO, A CIÊNCIA E A CULTURA, 2006): inadequada consciência pública ou despolitização das discussões e deliberações (WESTER; MERREY, 2005); envolvimento limitado das comunidades e setores privados para planejamento e orçamento; falta de recursos para operar (KAUFMANN et al., 1999); fragmentação institucional (THEODORO, 2002); inadequação de políticas públicas integradas (LISBOA, 2012); visão da água apenas como recurso (CASTRO, 2007); outras situaçôes particulares.

E o aumento crescente do interesse pela gestão na referida bacia acontece tanto pela gravidade ambiental que tem vinculação ao tema, como também pelo aporte financeiro que está mais disponível atualmente para projetos e serviços ambientais. Nesse sentido vale destacar que, para os especialistas ouvidos, há um grande disparate entre os recursos alocados para a gestão (na ordem de 15 milhôes de dólares anuais, de acordo com o Plano Plurianual de Aplicação da AGBPV) e os valores reais necessários à recuperação ambiental da bacia (que já recebeu mais de $600 \mathrm{mi}-$ lhôes de dólares de investimentos para tal até 2013 e que tem planejamento de investimento de mais 250 milhóes de dólares até 2015) (ABES, [2014?]).

Mas, deve-se esclarecer que não é esperado que os recursos oriundos da cobrança por uso de recursos hídricos sejam capazes de suprir todas as necessidades de investimentos na bacia, mas sim que sejam compreendidos como potenciais catalizadores para posterior mobilização de outros investimentos. Por exemplo, e tal como relatado em várias entrevistas, investimentos na realizaçáo de Planos Diretores de Recursos Hídricos, Planos Municipais de Saneamento, Planos Diretores Municipais etc podem efetivar adiante a captaçấo de recursos destinados ao saneamento, meio ambiente e recursos hídricos de forma mais ampla e eficiente do que até agora tem sido feito.

Porém, este processo de entendimento por parte do Estado e dos membros do CBHRV da complexidade em que se encontra a gestão da bacia e de como poderiam efetivamente participar dela ainda se encontra em consolidação. Ao mesmo tempo, há um reconhecimento de que, de forma geral, houve um aumento na participação dos atores sociais, inclusive ao nível municipal, o que foi, inclusive, um dos principais objetivos do comitê nos últimos anos - vide Figura 5.

O que foi diversas vezes relatado é que tal apro- 
ximação se deveu muito mais aos interesses vinculados com as possibilidades de captaçáo de recursos oriundos da cobrança por uso dos recursos hídricos (prevista na Lei Federal 9433/97) para os municípios do que por participar realmente da gestão - provavelmente se encontra aí mais um exemplo da influência da ação estatal no processo de mobilização institucional da gestáo hídrica ao direcionar o incremento da ação municipal local no comitê. Porquê mesmo que o recurso da cobrança náo venha do Estado, ele é um importante ator institucional para a definição dos critérios da aplicação dos recursos nos municípios.

Sendo esse um fenômeno relativamente novo segundo os entrevistados, tal desconfiança existe e apenas o tempo poderá demonstrar sua extensão. De acordo com o que foi pesquisado, o discurso é que a participação no CBHRV tem sido pouco a pouco melhorada em seu sentido qualitativo e deliberativo; ou seja, as pessoas e suas instituiçôes têm demonstrado mais preparo para, de verdade, participar do planejamento e execução de ações e tentar vencer o "déficit democrático" (SWYNGEDOUW, 2005) muitas vezes presente em modelos de gestáo democrática e participativa. A Figura 4 e a Figura 5, por exemplo, demonstram a intenção de que, via unidades de planejamento e de subcomitês, seja ampliada a capilaridade de atuaçấo administrativa e política ao longo da bacia hidrográfica.

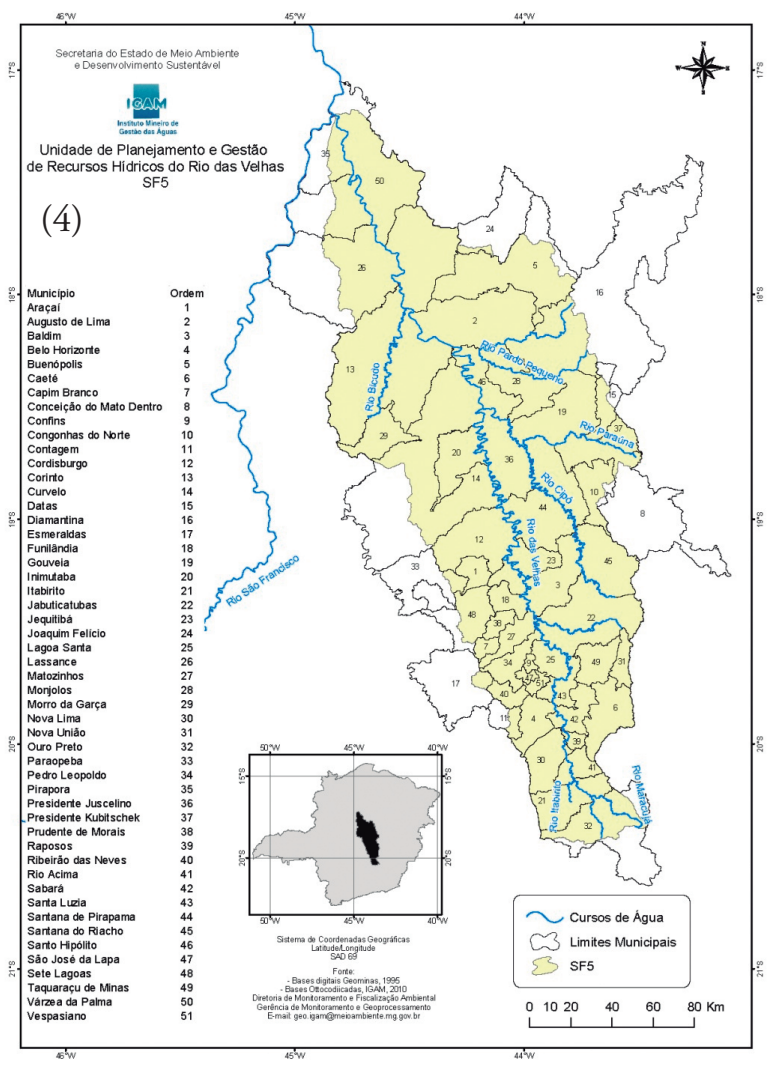

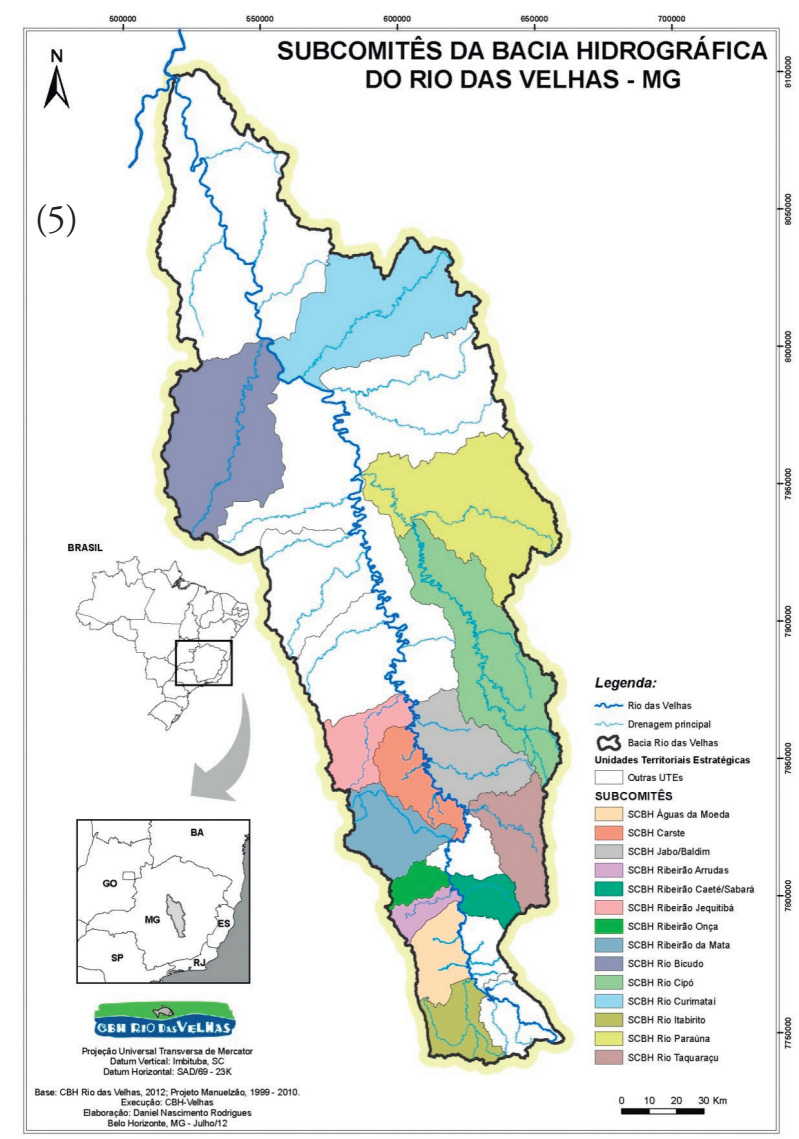

Figuras 4 e 5 - Unidades de Planejamento e Gestão de Recursos Hídricos (3) e Subcomitês da bacia hidrográfica do Rio das Velhas (4).

Fontes: www.igam.gov.br e

www.cbhvelhas.org.br/index.php/module-positions

Todavia, ao mesmo tempo as entrevistas mostraram que o comitê ainda precisa melhorar mais em tal aspecto para se aperfeiçoar; precisaria incorporar e refletir mais os movimentos sociais e ser capaz de criar triálogos institucionais (sociedade civil/mercado/ Estado). Tal fato relembra muito as discussóes oriundas de ARNSTEIN (1969) e também GOOCH e HUITEMA (2004) sobre os processos gradativos de participação. Seria então necessária a implementação de um processo contínuo de "planejamento estratégico"; "implementação e gerenciamento"; "aprendizagem e adaptação" (WARNER, 2007) para que os CBHs se concretizem e passem a gerar novos ambientes para tais conversaçóes, de maneira mais constante. Até porquê os sistemas (sociais, administrativos, econômicos, etc) são complexos e não haveria como todos os stakeholders participarem nem mensurarem todos os aspectos de governança envolvidos.

Por vezes foi identificada também no conteúdo das entrevistas a visão de que os órgãos gestores não atuam na mobilização de forma adequada para que o conceito de gestão democrática, descentralizada e 
integrada se torne realidade. E, ao se considerarem as análises sobre participação já descritas em GREN (2007) e WESTER e MERREY (2005), o processo de consolidação da participação social no comitê pesquisado ainda é longo e frágil frente à estrutura e interesse de ação estatal, que muda suas ações para manter seu nível de controle, visto que é, provavelmente, o principal ator na gestão institucional (SWYNGEDOUW, 2005). Da mesma forma, as organizaçôes atualmente refletem as interaçôes interpessoais de seus constituintes, o que demanda no processo de construção da boa governança institucional que lideranças sejam formadas e/ou consolidadas para se evitar que os processos sociais sejam interrompidos (WARNER, 2007). No estudo de caso do CBHRV, por exemplo, identificaram-se na pesquisa de campo e nas entrevistas as dificuldades em se estabelecer novas lideranças para a gestáo institucional e local dos recursos hídricos. Cabe destacar, porém, que o número de instituiçõos diferentes participantes tem aumentado nas reunióes do comitê em questão, assim como nos últimos processos eleitorais realizados para os mandatos de 2007-2013 e 2013-2017).

Ou seja, a constituição de uma arena de multi participantes, tal como os CBH's (WARNER, 2007) é geralmente controversa na medida em que seria uma "situação artificial" na qual as negociaçôes se dão por meio das preferências sobre o quê ou quem deve ser incluído (RÖLING; MAARLEVELD, 1999). Isso conduz à observação sobre a importância de capacitação para a participação, visto que ela neste sentido seria, de alguma forma, seletiva. Pois alguns membros são profissionais, treinados e remunerados para tal (Estado, setor produtivo) e outros são por vezes voluntários e que podem sofrer assimetrias informacionais e afins.

Só que a existência de capacitação ou treinamentos deve levar em consideração a formação de lideranças que (auto)sustentem os CBHs adiante e consolidem a governança hídrica e política. Por outro lado, interessante notar que os processos participativos (e talvez até os próprios comitês de bacia em geral), se não são adequadamente estruturados e conduzidos, podem retirar poder dos grupos participantes na medida em que alguns deles sejam cooptados por outros melhor estruturados (financeiramente, economicamente e, principalmente, politicamente, etc) (ABERS, 2010).

Tal situação pode gerar, inclusive, a auto-exclusão de grupos sociais que acreditam ser esses espaços pro- cedimentos hegemônicos e não de integração (TORTAJADA, 2001). Contudo, os atores sociais também podem atuar em paralelo ao CBHRV ou apenas em algumas situaçôes determinadas, como forma de se manterem autônomos das decisões a serem tomadas.

Todos estes exemplos sinalizam que não há uma temporalidade para que modelos tais como os de comitês comecem a gerar resultados para a gestáo hídrica (leia-se aqui maior interação, troca de experiências, formação de plano de trabalho etc), podendo demorar até anos para retirar as instituições de seu arranjo tradicional estabelecido (THEODORO, 2002; THEODORO; MARQUES, 2014). Ao mesmo tempo, o comitê pode ter uma governança insuficiente e mesmo assim gerar resultados para a gestão hídrica, o que, no longo prazo, também sinaliza um amadurecimento da forma de se fazer a gestão dentro do mesmo. Da mesma forma, a existência de redes de suporte técnico, humano, enfim, de capacitaçáo e monitoramento da governança envolvida nos processos é, aparentemente, um fator fundamental para que os comitês sejam eficientes, além de poderem garantir sua legitimidade frente aos atores sociais envolvidos nos processos de tomada de decisões (ABERS; KECK, 2013).

Isto nos leva a outro ponto de importância ao se analisar o conteúdo das entrevistas, que são as possíveis práticas diferenciadas existentes. Cabe ressaltar aqui mais uma vez que se entende por práticas diferenciadas o rol de atividades que não são usualmente adotadas no cotidiano dos comitês. Não poderiam ser consideradas como inovadoras simplesmente porquê se mostram mais como adaptaçóes sui generis para cada contexto do que a inclusão de procedimentos novos ao processo de gestão como um todo. Daí, o que se verificou é que o que existem seriam oportunidades de inovação mais do que um processo de planejamento de inovação institucional em si.

Dentre esses momentos pode-se identificar que, tanto a partir dos relatos obtidos nas entrevistas, quanto na observação participante realizada junto ao CBHRV e na AGBPV e também na variada documentação técnica pesquisada, esses acontecimentos seriam:

a) A divisão quatripartite (sociedade civil/grandes usuários/poder público estadual/poder público municipal), fruto do intento de se agregar mais as demandas locais que possam dar força aos municípios e dentro do planejamento do comitê em criar subcomitês; 
b) Criação de Câmaras Técnicas (CTs) para aprimorar qualitativamente as discussóes geradas, sendo que as 04 atuais tem itens de discussão cada vez mais direcionados ao planejamento de longo prazo do comitê ;

c) Redefinição do território da bacia em Unidades Territoriais Estratégicas (UTEs) - a partir das características das Figuras 4 e 5, com mais coerência demográfica, organizacional e geográfica da bacia (e que surgiu por meio de diálogos entre o CBHRV e AGBPV);

d) Manutenção da presidência do comitê no segmento da sociedade civil, de forma a solidificar a característica de participação democrática;

e) Aumento de parcerias institucionais para as áreas de formação educacional e técnica para a gestão de recursos hídricos, com vistas ao aprimoramento analítico e participativo dos membros e náo membros do comitê (Agência Nacional de Águas (ANA); Conselho Regional de Engenharia e Agronomia (CREA); Associação Brasileira de Engenharia Sanitária e Ambiental (ABES), dentre outras).

Porém, cabe destacar, em todos estes posicionamentos, há níveis de participação e controle estatal que, por vezes, possuem mais capacidade de intervenção do que de diálogo institucional, possibilidade já levantada em Swyngedouw (2005). Sendo assim, de forma geral identificaram-se os seguintes resultados a partir de toda a triangulaçáo de métodos aplicada, tendo-se aqui como base também as análises realizadas pela análise de conteúdo dos itens mais frequentes relatados nas entrevistas com lideranças do setor:

\section{CONCLUSÓES}

A partir do que foi proposto na introdução deste trabalho, ou seja, de se tentar identificar as principais restriçóes e potencialidades existentes para o avanço dos processos de gestáo democrática e participativa nas políticas públicas de recursos hídricos pelo estudo de caso do CBHRV, várias conclusóes se mostraram possíveis de serem apresentadas. Acredita-se que este trabalho abra, igualmente, perspectivas de aprofundamento teórico e metodológico.

Dentre essas conclusóes, primeiramente, cabe aqui reforçar o ponto da ainda necessária consolidação dos processos de participação e controle social que são vinculados ao gerenciamento de recursos hí- dricos em Minas Gerais e no CBHRV em particular. Devido aos fatos relatados anteriormente, a estrutura de acompanhamento e influência de um $\mathrm{CBH}$ frente à estrutura de atuação e controle do Estado ainda é díspare e se encontra em processo de consolidação. Pois a realização do preceito da "boa governança" em um cenário ainda tão desigual, dificilmente poderá gerar mudanças significativas, mesmo com os diversos exemplos de tentativas de inovaçáo institucional propostas e implantadas pelo CBHRV. Ou seja, a autonomia táo desejada pelos atores sociais, principalmente aqueles oriundos da sociedade civil, é muitas vezes reprimida em nome dos interesses de atuação estatal que, eventualmente, não exerce um reconhecimento das demandas desses em suas definiçóes de agenda ambiental, tal como relatado sobre alguns conflitos de interesses existentes.

$\mathrm{O}$ que se percebeu afinal, após as pesquisas de campo e também as análises documentais e afins é que há realmente uma relação paradoxal entre as demandas governamentais que visam ao desenvolvimento de um modelo mais integrado e descentralizado de gestão, mas que, ao mesmo tempo, deixa que o mesmo aconteça apenas na medida em que não emperre seus interesses de agenda política. Ou seja, há mesmo lacunas na gestão presente no cenário da gestâo presumidamente democrática e participativa no comitê estudado, uma vez que a influência estatal por vezes se faz presente quando há resistência aos seus interesses (como no caso da crise institucional verificado no ano de 2012).

Objetivamente, há uma autonomia para a gestão democrática e participativa no discurso, mas o que se identificou de fato foi uma relevante presença do Estado nas práticas do comitê pesquisado. Exemplos para isso não se prendem somente ao controle sobre as açôes do CBHRV no que tange às determinaçóes de outorgas ou cobranças por uso de recursos hídricos, mas também na estruturação de mobilização social e projetos de intervençấo da bacia. Ou seja, ao mesmo tempo em que foi o gerador da estrutura de gestáo de recursos hídricos em Minas Gerais, e dentro de uma lógica exógena de desenho institucional, o Estado também se comporta como seu definidor de atuação, mesmo que, pretensamente, se tenha um contexto democrático e participativo de gerenciamento.

Significa, por um lado, uma demonstração do imenso caminho a ser ainda trilhado pelos atores sociais institucionais envolvidos com a gestâo hídrica estadual em busca de uma autonomia real de consulta e 
Quadro 1 - Participação, Transparência e Práticas Diferenciadas no CBHRV

\begin{tabular}{|c|c|c|}
\hline Critérios & Possibilidades & Restriçóes \\
\hline Participação & $\begin{array}{l}\text { a) O avanço da participação no comitê } \\
\text { é quase um consenso e tem tudo para } \\
\text { continuar. } \\
\text { b) Há mais diversidade de participantes e } \\
\text { com linhas de atuação mais diversa. } \\
\text { c) Existe demanda reprimida em relação } \\
\text { à capacidade de adesão e participação de } \\
\text { novos membros nos } 04 \text { segmentos, pois a } \\
\text { importância do tema se mostra crescente. }\end{array}$ & $\begin{array}{l}\text { a) Como o modelo possui um forte laço } \\
\text { estatal, nem sempre o processo se mostrou tão } \\
\text { democrático e participativo assim. } \\
\text { b) Muitas vezes o aumento do número e } \\
\text { diversidade de atores não significa um diferencial } \\
\text { qualitativo para a gestão. Também não implica em } \\
\text { participaçáo mais democrática. Ainda há muito } \\
\text { utilitarismo na dinâmica do comitê, assim como } \\
\text { participação sem representação efetiva algumas } \\
\text { vezes. }\end{array}$ \\
\hline Transparência & $\begin{array}{l}\text { a) O aumento de estrutura do CBHRV e } \\
\text { da AGBPV possibilitou um incremento } \\
\text { na transparência sobre o planejamento } \\
\text { e execução das açóes institucionais e } \\
\text { operacionais. } \\
\text { b) A gestão com base em planejamento } \\
\text { (com planos de aplicação de recursos) tem } \\
\text { acontecido mais frequentemente. } \\
\text { c) Os conflitos se tornaram mais } \\
\text { transparentes e possuem agora mais arenas } \\
\text { de discussáo do que no formato original, } \\
\text { sendo o aumento do número de câmaras } \\
\text { técnicas e a realizaçáo de reunióes plenárias } \\
\text { em outras cidades, exemplos claros dessas } \\
\text { novas dinâmicas. }\end{array}$ & $\begin{array}{l}\text { a) Nem todos os participantes do CBHRV têm } \\
\text { conhecimento ou direcionamento adequado para } \\
\text { captar e entender de forma global o processo de } \\
\text { gestão. Ou seja, a estrutura tem crescido mas } \\
\text { a visão deve ser do processo como um todo } \\
\text { (planejamento, reuniões, decisóes etc). } \\
\text { b) A prática de planejamento mais sistemático } \\
\text { e de mais longo prazo ainda está a se consolidar } \\
\text { e não é apropriada por todos os membros e da } \\
\text { mesma forma. } \\
\text { c) Tão somente a existência de mais espaços } \\
\text { de discussão não assegura que os processos } \\
\text { institucionais geraráo consensos ou que serão } \\
\text { rapidamente admitidos e/ou implementados. }\end{array}$ \\
\hline $\begin{array}{l}\text { Práticas } \\
\text { diferenciadas }\end{array}$ & $\begin{array}{l}\text { a) A gestáo ao nível das microbacias } \\
\text { (sub-comitês) tem se revelado bastante } \\
\text { animadora, sendo que a mobilização, } \\
\text { também ao nível local, possibilitou maior } \\
\text { motivação e interesse pelo CBHRV. } \\
\text { b) A implantação de projetos ambientais e } \\
\text { de saneamento, principalmente com foco na } \\
\text { gestão municipal tem sido considerada um } \\
\text { avanço. } \\
\text { c) A criação de Câmaras Técnicas (CT's) } \\
\text { que, teoricamente, dão suporte à resolução } \\
\text { de conflitos } \\
\text { d) Há a manutenção de um poder de } \\
\text { decisão de forma quatripartite, com } \\
\text { diferenciação entre poder público estadual } \\
\text { e municipal para aumentar o poder de voz } \\
\text { local. }\end{array}$ & $\begin{array}{l}\text { a) As inovaçóes estão por vezes atreladas às } \\
\text { amarras da legislaçáo, principalmente os processos } \\
\text { licitatórios. } \\
\text { b) Os municípios não têm se mostrado } \\
\text { estruturados em termos técnicos, humanos e } \\
\text { materiais para conseguirem alocar recursos e } \\
\text { projetos, ainda, para suas necessidades. } \\
\text { c) Os elementos técnicos fornecidos pelas CT's } \\
\text { para auxiliarem as decisóes políticas precisam ser } \\
\text { cada vez mais incorporadas na agenda do comitê. } \\
\text { d) Existem diferenças muito grandes de } \\
\text { dinâmica e de interesses na forma como Estado e } \\
\text { municípios vêem o comitê e o sistema de gestão } \\
\text { de recursos hídricos, pois eles têm estruturas } \\
\text { operacionais, recursos humanos e materiais } \\
\text { distintos. }\end{array}$ \\
\hline
\end{tabular}

deliberação de açóes e, por outro lado, denota como a boa governança também se encontra inserida em uma realidade de controle institucional muito presente, a confirmar o pressuposto original deste trabalho. O que pode ser identificado a partir desta interação poderia ser traduzido, em nível de um desenvolvimento institucional, em três níveis de articulação que precisariam ser fortalecidos: 1) um sistema organizacional que se conduza por meio de uma gestão eficiente e eficaz; 2) melhore os mecanismos de suporte de decisão por meio da incorporação e interação das diversas experiências e realidades existentes na bacia, principalmente ao nível local; 3) fortalecimento das propostas institucionais para utilização da água em vários níveis (municipal, estadual, federal), através de uma gestão compartilhada e com planejamento integrado de longo prazo. 
Ao se pensar a boa governança para a gestão de recursos hídricos na bacia específica, ficou a pesquisa assim a vislumbrar um contexto paradoxal de autonomia de açóes políticas e sociais em alguns momentos da institucionalização do modelo de gerenciamento mas, por outro, a penumbra do controle estatal a todo o instante denota e impóe limites à mesma estrutura que anteriormente próprio, Estado, contribuir para criar. E essa necessidade de se manter uma agenda com forte base institucional de Estado se revelou ainda constante de acordo com as triangulaçóes de análise realizadas. Superar as restrições já descritas em direção às possibilidades postas pelo conceito de gestão descentralizada, democrática e participativa é um desafio que demanda, sem dúvidas, aprofundamentos permanentes de pesquisa e ação social. No caso do CBHRV, por um lado o aumento e manutenção do diálogo com os setores estatais terá de ocorrer, mesmo à custa de vários embates, como por outro lado a recuperação de uma visão de desenho institucional sólida e mais autônoma em relação aos interesses da agenda política governamental será provavelmente muito necessária.

Assim, percebe-se que o tradicional modelo de gestáo adormece nas máos dos expertos e a ampliação participativa é um processo que demanda multi-dimensóes e intersetorialidade. Mas o grande atrativo dos $\mathrm{CBHs}$ não se relaciona apenas por sua proposta de inserção de atores e sim por: 1) se compor como um modelo alternativo de resolução de conflitos; 2) poder ser considerado como um modelo de gerenciamento adaptativo; 3) ser um caminho para possibilitar maior democratização e empoderamento da governança. Este elenco de possibilidades demostra que o CBHRV pode se consolidar como um espaço de mediação rumo a políticas públicas de boa governança. Se tal irá se confirmar é uma interrogação que somente será superada na medida em que autonomia dos processos de gestáo de recursos hídricos no referido comitê for mais assegurada e menos controlada por meio de triálogos, planejamento e execução adequada de açôes, ou seja, a governança em ação.

\section{REFERÊNCIAS}

ABERS, Rebecca Neaera. Água e Política: atores, instituiçóes e poder nos Organismos Colegiados de Bacia Hidrográfica no Brasil. São Paulo: Annablume, 2010.

ABERS, R. N. et al. Inclusão, deliberação e controle: três dimensôes de democracia nos comitês e consórcios de ba- cias hidrográficas no Brasil. Ambiente \& Sociedade. v. 12, n. 1. jan-jun. 2009.

ABERS, Rebecca Neaera; KECK, Margaret E. Practical Authority. New York: Oxford, 2013.

AGÊNCIA NACIONAL DE ÁGUAS. Conjuntura dos recursos hídricos no Brasil: informe 2012. Edição especial. Brasília: ANA, 2012.

ARNESTEIN, S. R. A Ladder of Citizen Participation. JAIP, v. 35, n. 4, july 1969, p. 216-224.

ASSOCIAÇÃO BRASILEIRA DE ENGENHARIA SANITÁRIA E AMBIENTAL. Programa para revitalizaçáo da bacia do Rio das Velhas é finalista do Prêmio Furnas Ouro Azul. [2014?]. Disponível em: <http://www.abes-mg. org.br/visualizacao-de-clippings/pt-br/ler/3046/programa -para-revitalizacao-da-bacia-do-rio-das-velhas-e-finalista-do -premio-furnas-ouro-azul>. Acesso em: 13 jul. 2014.

BANCO MUNDIAL. Governance and Development. Washington: [s.n.], 1992.

BARDIN, Laurence. Análise de conteúdo. Lisboa: Ediçôes 70, 1994.

BECK, Ulrich; GIDDENS, Anthony; LASH, Scott. Modernizaçáo Reflexiva: política, tradição e estética na ordem social moderna. São Paulo: Unesp, 1997.

CAMARGOS, Luiza de Marillac Moreira (coord.). Plano diretor de recursos hídricos da bacia hidrográfica do rio das Velhas: resumo executivo - dezembro 2004. Belo Horizonte: Instituto Mineiro de Gestão das Águas, Comitê da Bacia Hidrográfica do Rio das Velhas, 2005.

CASTRO, J.E. Water governance in the twentieth-first century. Ambiente \& Sociedade. v. 10, n. 2, Jul-Dez. 2007.

COMITÊ DA BACIA HIDROGRÁFICA DO RIO DAS VELHAS. A bacia hidrográfica do Rio das Velhas. [2014?]. Disponível em : <http://cbhvelhas.org.br/a-bacia -hidrografica-do-rio-das-velhas/>. Acesso em: 24 out. 2014.

CUNHA, Eleonora Schettini M.; THEODORO, Hildelano Delanusse. Desenho Institucional, Democracia e Participation: conexões teóricas e possibilidades analíticas. Belo Horizonte: D’Plácido, 2014.

DOUROJEANNI, A.; JOURAVLEV, A. Gestión del agua a nivel de cuencas: teoría y práctica. [S.l.]: CEPAL, 2002.

FLICK, Uwe. Qualidade na pesquisa qualitativa. Porto Alegre: Artmed, 2009.

GIDDENS, Anthony. A política da mudança climática. Rio de Janeiro: Zahar, 2010. 
GOLAFSHANI, Nahid. Understanding reliability and validity in qualitative research. The Qualitative Report. v. 8, n. 4, 2003.

GOOCH, Geoffrey D.; HUITEMA, David. Improving governance through deliberative democracy: initiating informed public participation in water governance policy processes. In.: STOCKHOLM WATER SYMPOSIUM AND WORLD WATER WEEK, 14., Stockholm, 2004. Proceedings..., Stockholm: SIWI, 2004.

GOULART, Eugênio Marcos Andrade (org.). Navegando o Rio das Velhas das Minas aos Gerais. Vol. I e II. Belo Horizonte: Instituto Guaicuy - SOS; Rio das Velhas: UFMG, 2005.

GREEN, Colin. Mapping the field: the landscapes of governance. London: Middlesex University, 2007.

KAUFMANN, D; KRAAY, A.; ZOIDO-LOBATÓN, P. Governance matters. [S.1.]: The World Bank, 1999.

LISBOA, Apolo Heringer. Projeto Manuelzão: uma estratégia socioambiental de transformação da mentalidade social. 274 f. 2012. Tese (Doutorado) - Universidade Federal de Minas Gerais. Belo Horizonte, 2012.

MAYNTZ, Renate. Nuevos desafíos de la teoría de Governance. Barcelona: Instituto Internacional de Governabilitat de Catalunya, 2000.

MINAYO, Maria Cecília de Souza (org.). Pesquisa social: teoria, método e criatividade. Petrópolis, RJ: Vozes, 2012.

MINAYO, Maria Cecília de Souza et al. Avaliaçáo por triangulaçáo de métodos: abordagem de programas sociais. Rio de Janeiro: Fiocruz, 2005.

PROJETO MANUELZÃO. Subcomitês e mobilizaçáo social. [2012?]. Disponível em: <http://150.164.90.128/ mobilizacao/subcomites. 2011>. Acesso em: 05 set. 2012.

RICHARD, Sophie; RIEU, Thierry. Une approche historique de la gouvernance pour éclairer la gestion concertée de l'eau en France. IWRA WORLD WATER CONGRESS, 13., Montpellier, 2008. Proceedings... Montpellier: IWRA, 2008.

ROGERS, Peter; HALL, Alan W. Effective water governance. Stockholm: Elanders Novum, 2003. (The Background papers, n. 7)

RÖLING, Niels; MAARLEVELD, Marleen. Facing strategic narratives: an argument for interactive effectiveness. Agriculture and Human Values. n. 16, p. 295-308, 1999.

SOARES, Samira Iasbeck de Oliveira. A mediaçáo de conflitos na gestáo de recursos hídricos no Brasil. 160 f. 2008. Dissertação (Mestrado) - Programa de Ciências Ambientais, Universidade de São Paulo. São Paulo, 2008.

SWYNGEDOUW, Erick. Governance Innovation and the Citizen: The Janus face of governance-beyond-the-State. Urban Studies, v. 2, n. 11, 2005.

TORTAJADA, Cecilia. Institutions for integrated river basin management in Latin America. Water Resources Development, v. 17, n. 3, p. 289-301, 2001.

THEODORO, Hildelano Delanusse. Instituiçóes e gestáo de recursos hídricos em Minas Gerais. Dissertação (Mestrado) - Departamento de Economia Rural, Universidade Federal de Viçosa., 2002.

THEODORO, Hildelano Delanusse; MARQUES, Danilo. Análise de modelos institucionais de recursos hídricos, com foco em Minas Gerais, Brasil. Revista Sustentabilidade em Debate, v. 5, n. 1, p. 117-135, jan/abr. Brasília: UnB, 2014.

TUCCI, C. E. M. Gestão da Água no Brasil. Brasília: UNESCO, 2001.

ORGANIZAÇÃO DAS NAÇÓES UNIDAS PARA EDUCAÇÃO, CIÊNCIA E CULTURA. Water: a shared responsability. [S.1 : s.n.], 2006. Report 2.

WARNER, Jeroen. Multi-Stakeholder Platforms for Integrated Water Managment. The Netherlands: Ashgate Publishing Limited, 2007.

WESTER, Philippus; SHAH, Tushaar; MERREY, Douglas J. Providing Irrigation Services in Water-Scarce Basins: Representation and Support. [S.1 : s.n.], 2005. 